Article

\title{
The Impact of Dietary Grape Seed Meal on Healthy and Aflatoxin B1 Afflicted Microbiota of Pigs after Weaning
}

\author{
Iulian A. Grosu, Gina C. Pistol ${ }^{\circledR}$, Ionelia Taranu ${ }^{\mathbb{D}}$ and Daniela E. Marin* \\ Laboratory of Animal Biology, National Institute for Research and Development for Biology and Animal \\ Nutrition, Calea Bucuresti no. 1, Balotesti, Ilfov 077015, Romania; grosu.iulian@ibna.ro (I.A.G.); \\ gina.pistol@ibna.ro (G.C.P.); ionelia.taranu@ibna.ro (I.T.) \\ * Correspondence: daniela.marin@ibna.ro; Tel.: +40-21-351-2082; Fax: +40-21-351-2080
}

Received: 23 November 2018; Accepted: 2 January 2019; Published: 8 January 2019

check for updates

\begin{abstract}
The study investigated the effect of grape seed (GS) meal, aflatoxin (AFB1), or their combination on the large intestine microbiota of weanling piglets. Twenty-four piglets were allocated into four groups based on diet composition: (1) Control group; (2) AFB1 (320 g/ $\mathrm{kg}$ feed) group; (3) GS group ( $8 \%$ inclusion in the diet); (4) AFB1 + GS group. After 30 days of experiment, the colon content was used for microbiota analyses; after isolation of total bacterial genomic DNA, V3/V4 regions of the $16 \mathrm{~S}$ rRNA amplicons were sequenced using the Illumina MiSeq platform. The raw sequences were analyzed using the v.1.9.1 QIIME pipeline software. 157 numbers of OTUs were identified among all four dietary groups with 26 of them being prevalent above $0.05 \%$ in the total relative abundance. GS and AFB1 increase the relative abundance of phylum Bacteroidetes and Proteobacteria, while decreasing the Firmicutes abundance in a synergic manner as compared with the individual treatments. An additive or synergistic action of the two treatments was identified for Lactobacillus, Prevotella and Campylobacter, while rather an antagonistic effect was observed on Lachnospira. The action mechanisms of aflatoxin B1 and grape seed meal that drive the large intestine microbiota to these changes are not known and need further investigations.
\end{abstract}

Keywords: microbiota; grape seed; aflatoxin B1

Key Contribution: Concomitant administration of GS and AFB1 caused a significant shift in the microbial community by significantly increasing the relative abundance of phylum Bacteroidetes and Proteobacteria; while decreasing the abundance of Firmicutes.

\section{Introduction}

Aflatoxins are an important group of mycotoxins mainly produced by the Aspergillus flavus and parasiticus species, which contaminates a large quantity of the world's crops, colonizing cereals (especially maize) and other important animal and human food [1,2]. Extensive studies show that aflatoxin B1 is the most harmful of the aflatoxin group, due to its potent toxicity and immune toxicity when is metabolically activated in the liver [2,3]. Chronic exposure to low levels of aflatoxins is a risk factor for hepatocellular carcinoma; based on toxicological data AFB1 has been categorized as a group 1 human carcinogen by the International Agency for Cancer Research [4]. A pig with a diet rich in cereals is very exposed to aflatoxins [5]. Extreme effects can lead to death, but the greatest impact comes from reduced reproductive potential, suppressed immune function, reduced performance, and various pathological effects on organs and tissues [6]. At lower concentrations, AFB1 induced depressed appetite, lower growth rate and lower feed conversion efficiency, decreased proteosynthesis, 
and immunosuppression especially in younger pigs. An increase in free radicals, leading to unusual oxidative damage and lipid peroxidation, which triggers cell apoptosis was observed [2].

On the other hand, remarkable efforts have been made to develop novel prevention/intervention strategies against AFB1-induced adverse health effects, including liver cancer risks and growth in farm animals. Among the prevention strategies used for the mitigation of AFB1 negative effects, nutritional strategies are the most promising. The nutritional strategies may consist in the use of antioxidants, preservatives and natural inhibitors, activated carbons, dietary fibers, hydrated sodium calcium aluminosilicate, bentonite, zeolites, lactic acid bacteria etc. [7].

Grape seeds are waste products of the winery and grape juice industry [8]. They have recently been used for the production of grapeseed oil which is a valuable food product and a cosmetic ingredient [9]. The seeds contain fatty acids, lipids, amino acids, carbohydrates, and complex fibers, and $4-10 \%$ of polyphenols depending on the variety [10]. Grape seed meal is the residual from the grape seeds after oil has been extracted.

Flavonoids represent the predominant class of polyphenols found in grape seed meal, including gallic acid, catechin, epicatechin, gallocatechin, epigallocatechin, and procyanidins [11]. These compounds have been of great interest to the food industry due to their benefits: their anti-aging, anti-inflammation, anti-carcinogenic, anti-mutagenic, anti-ulcer, antiatherogenic, and anti-microbial effects and as inhibitors of human low density lipoprotein oxidation [12]. Recent in vitro studies have shown that oxidized polyphenols resulting from tea fermentation can bind AFB1, and that nearly $85 \%$ of AFB1 can be transformed into complexed AFB1 [13]. According to the same study, the intestinal absorption of the complexes AFB1-oxidized polyphenols was inhibited in the rat intestine.

Incorporation of industrial by-products in animal diets is an economically and environmentally viable practice for livestock production [14]. The major limitations of using grape seed meal in monogastric feed are the high level of lignified cell wall fraction and the high tannin content. However, in vivo and in vitro studies carried out over the last few years have shown the beneficial effects of grape seed bioactive compounds administration due to their antioxidant and antimicrobial activity [15].

Oxidative stress caused by AFB1 may be one of the underlying mechanisms for AFB1-induced cell injury [5]. AFB1 enhances ROS formation and causes lipid peroxidation, oxidative DNA and protein damage that can finally lead to tumorigenesis [5]. On the other side, grape seeds have shown important antioxidant properties due to the high polyphenols content [16]. Dietary polyphenols are one of the most important groups of natural antioxidants found in human and animal diets and their antioxidant activity is not only based on directly reacting with ROS but also agonistically activating cellular signaling pathways involved in oxidative stress [17].

Since oxidative stress plays an important role in the toxicity mechanism of AFB1, some antioxidant compounds present in the grape seed meal could be of use in the prevention or at least diminishing the adverse effects of chronic AFB1 toxicity in animals. Some studies have shown that flavonoids as flavone, flavanone and tangeretin can act as an anti-initiators of hepatocarcinogenesis induced by AFB1 through the increase of activity of enzymes involved in the detoxication of AFB1 (glutathione S-transferase, UDP-glucuronyl transferase), increased formation of AFB1-glutathione conjugates and inhibition of the formation of AFB1-DNA adducts. Also, as it was shown in a reconstituted microsomal monooxygenase system, polyhydroxylated flavonoids and phenolic acids can modulate chemical carcinogenesis induced by AFB1 through the inhibition of NADPH-cytochrome P450 reductase [18].

Gut microbiota is a dynamic community of several hundred primarily anaerobic bacteria with important consequences either harmful or advantageous to host physiology and animal performance [19]; these communities live in close proximity to each other developing mainly mutualistic or even symbiotic relationships between them and the host, the composition and abundance of species varying with age, gastrointestinal location, diet, stress, exposure to antibiotics and environmental factors [20]. It participates in the metabolism of the host and take part in the detoxification and metabolic waste excretion [21]. Only approximately 10\% of the ingested flavonoid glycosides are absorbed in the upper gastrointestinal tract [22]. Polyphenols cannot exert their 
beneficial effect in the absence of gut microbiota that can catabolize flavonoids in various kinds of catabolites using a large enzymatic equipment [23].

In recent years, next generation sequencing technologies have revealed all kinds of intricate connections among gut-microbiota, dietary composition and host health [24-26]. In this 3-way relationships, oral exposure to xenobiotics or dietary composition could lead to the modulation of gut microbiota, and the changes of gut-microbiota may further influence host health in a significant way [27].

Changing the gut microbiota metabolites, either through changing nutritional habits or by changing the microbiome itself, can also have the potential to mitigate a number of metabolic diseases $[17,28]$. After our knowledge there are no studies concerning the effect of the concomitant administration of aflatoxin and grape waste on microbiota composition.

The aim of this study was to investigate the AFB1 as a contaminant in feed for its effects at the level of microbiota and whether grape seed meal had the potential to modulate by itself the dynamics of microbiota in pig after weaning and to counteract the possible negative effects on microbiota of pigs fed diet contaminated with AFB1.

\section{Results}

\subsection{Body Weight and Diarrhea Score}

Piglets fed for 30 days with a diet contaminated with AFB1 registered a significantly lower body weight $(p<0.05)$ when compare either with control or GS group (Figure 1$)$. This effect was counteracted by the inclusion of $8 \%$ of GS meal into the diet contaminated with AFB1. Reported to the entire period of the experiment only $2.78 \%$ of the control piglets had diarrhea. In change, AFB1 was responsible for a higher percentage of piglets with diarrhea (16.67\%), while both GS and GS + AFB1 piglets had almost no diarrhea (Figure 2).

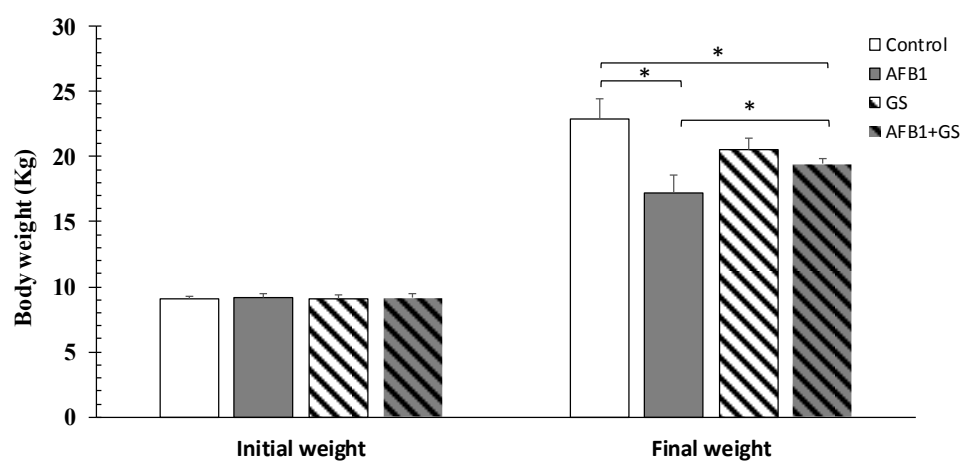

Figure 1. Effect of different dietary treatments of piglets' body weight. GS: grape seed; AFB1: aflatoxin B1. * indicate significant differences $(p<0.05)$ between groups.

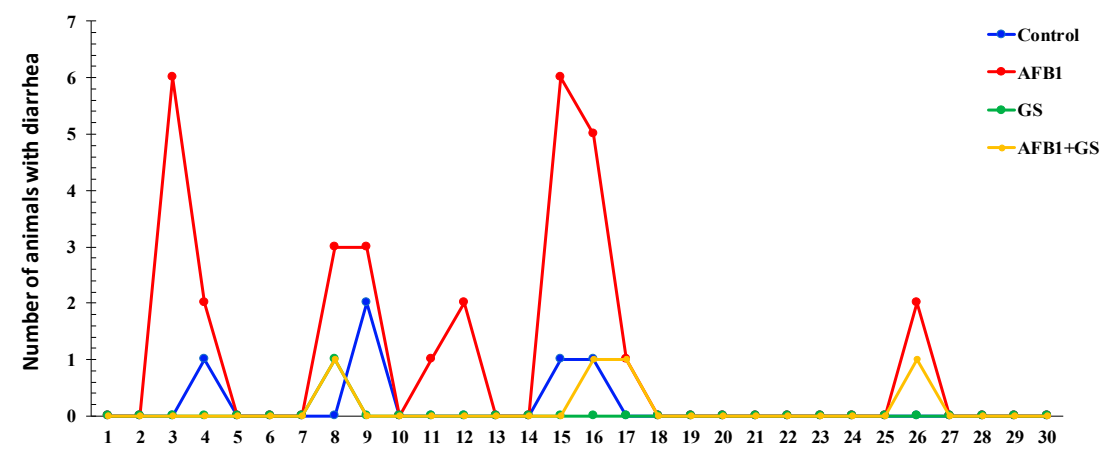

Figure 2. Effect of different dietary treatments on the number of piglets with diarrhea. GS: grape seed; AFB1: aflatoxin B1. 


\section{2. $16 S$ rRNA Gene Sequencing and Metagenomic Analysis}

The metagenomic analysis of gut microbiota revealed a total of 1,154,427 reads with the lowest sample count of 24,903 and the highest count of 93,622 and an average of 50,192 reads per sample of dietary group, respectively. To remove sampling depth heterogeneity, rarefaction on the OTU table was performed with a cut-off of 24,903 , the lowest number of reads recovered in a single sample which was used as the sample depth. More than $90 \%$ of sequences from each sample passed quality filtering, showing that the sequencing method is both robust and efficient.

\subsection{Alpha Diversity}

Dietary groups containing Grape Seed Meal, Aflatoxin B1 or both did not result in altered microbial community richness and diversity compared to the control group. The indices inspected included Chao1 (species richness) and PD_whole_tree (phylogenetic diversity units). The lack of influence on richness and diversity was evident at all phylogenetic levels (Figure 3A,B). There were no major community shifts caused by dietary treatments showed in either unweighted $(p=0.2019)$ or weighted ( $p=0.4817$ ) UniFrac (Figure 4 A,B respectively).
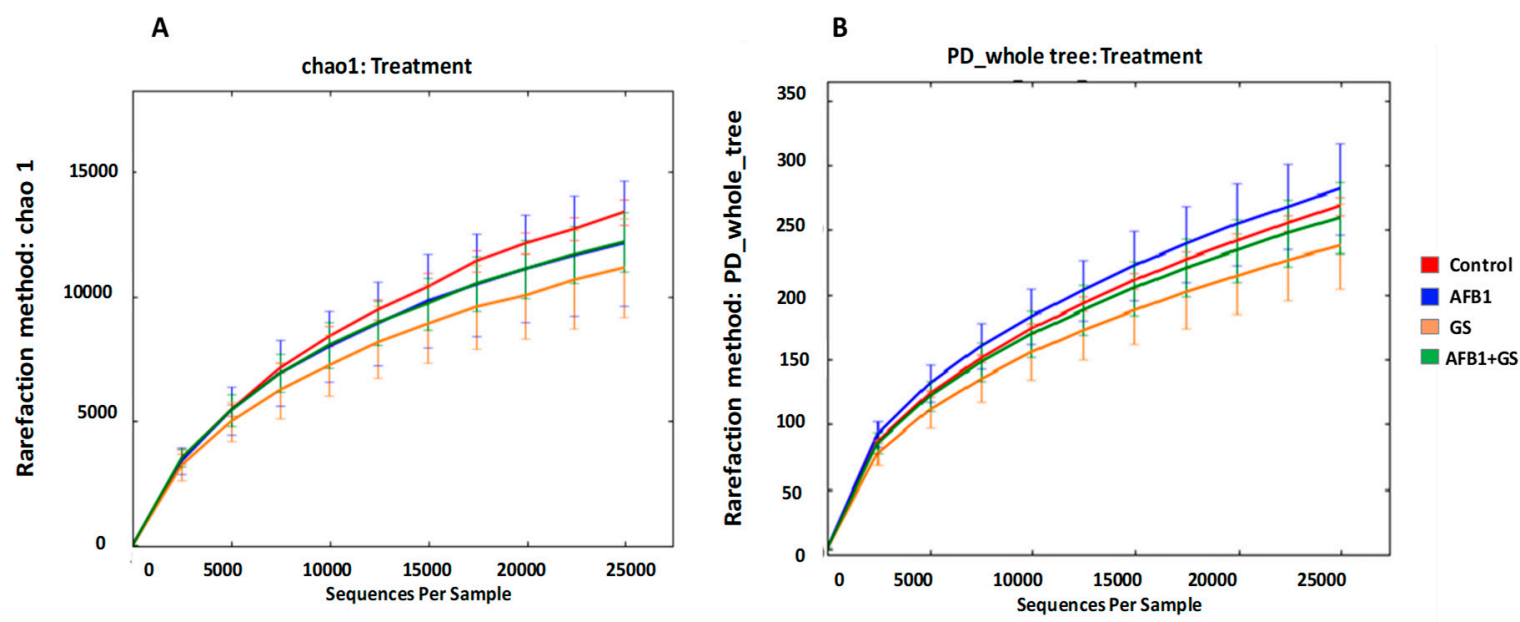

Figure 3. Analysis of alpha diversity in gut microbiota of weaning piglets fed with control diet, AFB1-treated, GS diet and GS + aflatoxin B1 (AFB1) diet. The diversity indices for each experimental group was predicted by Chao 1 (A) or by phylogenetic diversity (B). GS: grape seed; AFB1: aflatoxin B1.

A

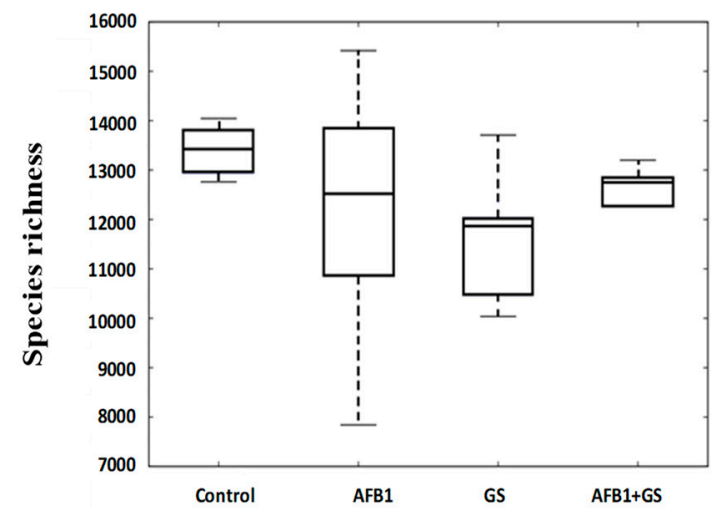

B

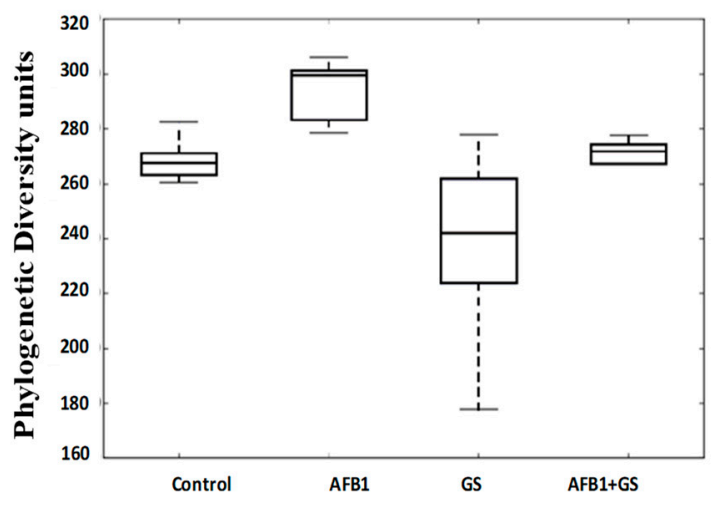

Figure 4. Alpha diversity box plots of Chao 1 (A) and of phylogenetic diversity (B) showing richness profiles for each experimental diet. GS: grape seed; AFB1: aflatoxin B1. 


\subsection{Beta Diversity}

The Unifrac method, of unweighted and weighted taxon abundances, was used for the construction of the principal coordinate analysis ( $\mathrm{PCoA}$ ) to enable the examination and visualization of the beta diversity within the colon. The Unifrac being phylogeny-based, Weighted-UniFrac takes into account the relative abundance of species/taxa shared between samples. Weighted UniFrac is also useful for examining differences in community structure, which aligned with our study goal. Explaining the low variance of the two axes $(22.43 \%$ and $10.19 \%)$ from the weighted plot can be done considering the multitude of factors that can influence the samples (Figure 5).

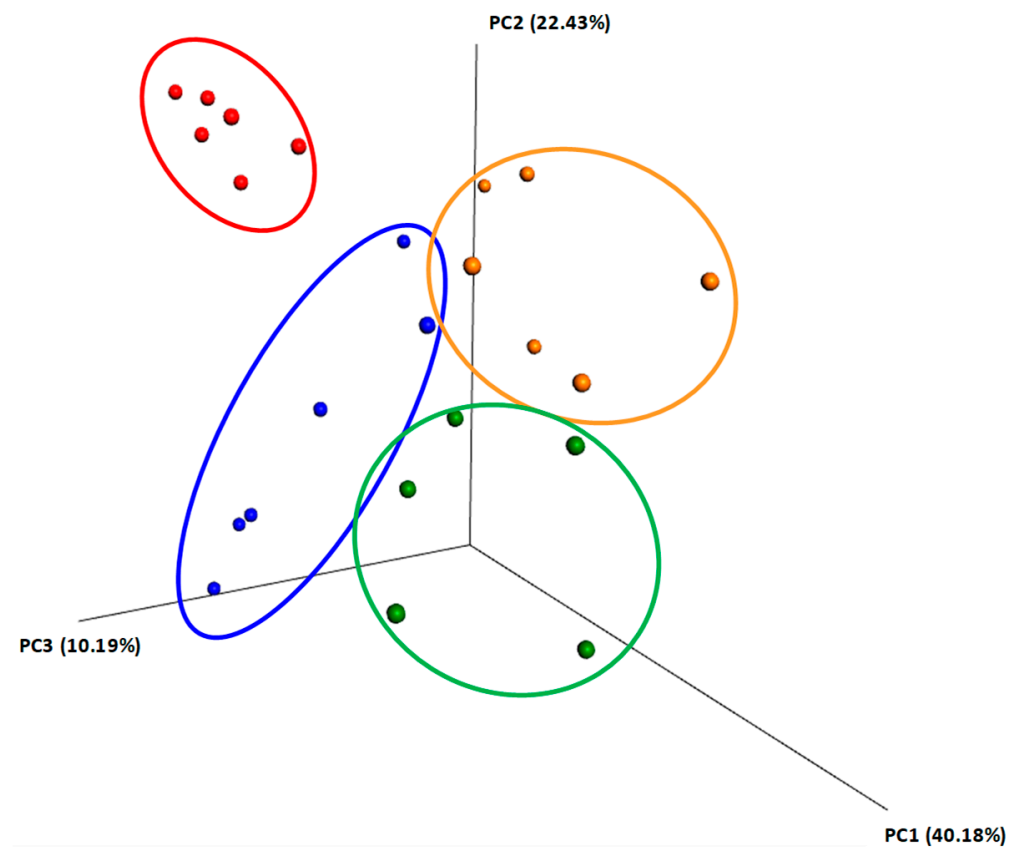

Figure 5. Principal component analysis plot based on OTUs found in the content of colon collected from weaning piglets fed different diets. Plot is based on unweighted Unifrac Distances. The amount of variance is depicted by the percentages in parentheses on each axis. Ellipses denote clustering according to each type of experimental diets: control (red), AFB1 (blue), GS (orange) and GS + AFB1 (green). GS: grape seed; AFB1: aflatoxin B1.

\subsection{Comparisons between Community Compositions}

The most highly represented phyla within the large intestine microbiota of the weaning piglets in the control group were Firmicutes $(58.33 \%)$, and Bacteroidetes $(34.51 \%)$, while phyla present in low abundance $(<0.01 \%)$ included Proteobacteria $(1.2 \%)$, Spirochaetes, Tenericutes, and Actinobacteria, with traces of Euryachaeota, Fibrobacteres, Cyanobacteria, and Deferribacteres (Figure 6).

The phylum Bacteroidetes was statistically and progressively increased in AFB1 and GS group when compared to control. The Firmicutes phylum was also significantly decreased by AFB1 and GS; the concomitant administration of AFB1 + GS have a synergic or additive effect on Firmicutes phylum.

In comparison, in the AFB1 group, Firmicutes had a $33.2 \%$ presence and Bacteroidetes $54.4 \%$, in GS group, Firmicutes accounted for $32.3 \%$ and Bacteroidetes $60.3 \%$ and in the AFB1 + GS group, Firmicutes had just a $12.5 \%$ presence while the Bacteroidetes reached $73.8 \%$. (Figure 7$)$. The relative abundance of the microbiota at the genus level identified Prevotella (21.93\%), Lactobacillus (24.8\%), Lachnospira (0.89\%) and Campylobacter $(0.55 \%)$ to be the most abundant in colon. In this study, there were also identified Megasphaera, Anaerovibrio, Trembayales, and Clostridiaceae (Figure 8). 


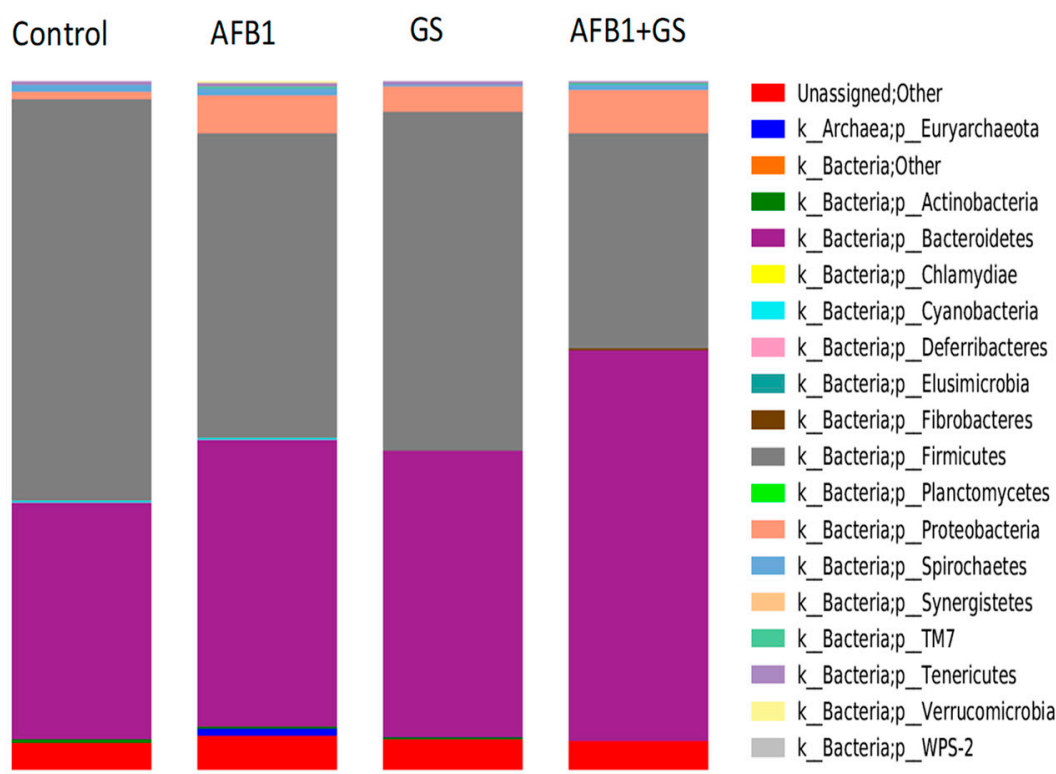

Figure 6. Relative abundances (\%) of bacteria phyla found in the content of colon collected from weaning piglets fed different experimental diets: control, AFB1, GS, and GS + AFB1. GS: grape seed; AFB1: aflatoxin B1.
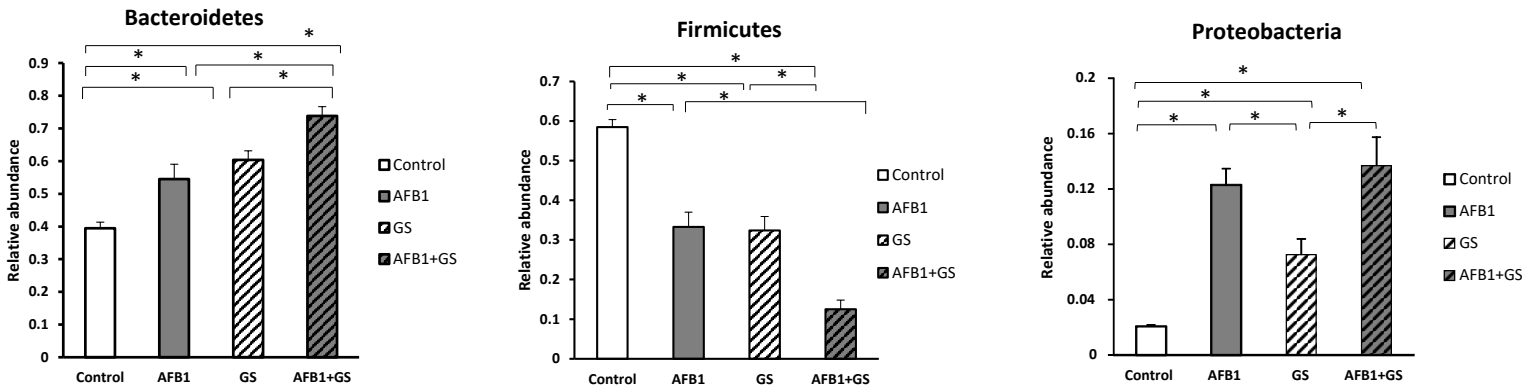

Figure 7. The relative abundances of the most important phyla found in the content of colon collected from weaning piglets. GS: grape seed; AFB1: aflatoxin B1. * indicate significant differences $(p<0.05)$ between groups.

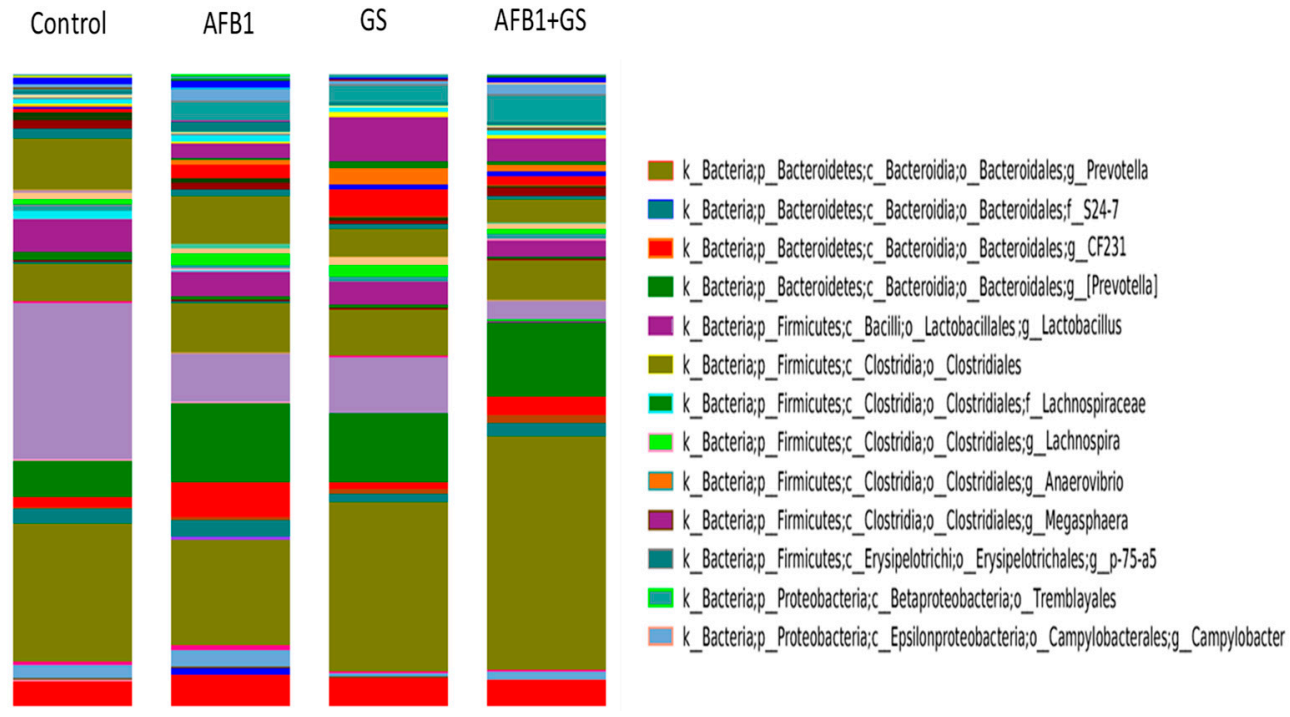

Figure 8. Relative abundances (\%) of bacteria genus found in the content of colon collected from weaning piglets fed different experimental diets: control, AFB1, GS, and GS + AFB1. GS: grape seed; AFB1: aflatoxin B1. 
As can be seen in the Figure 9, grape seed meal had a stimulating effect on Prevotella relative abundance, and GS seems to act synergistic with AFB1, as the highest relative abundance was observed in the AFB1 + GS1 (48.1\%) group ( $p<0.05)$ when compared to the Control $(25.3 \%)$ and GS group $(39.45 \%)$ As shown in Figure 9, both AFB1 and GS significantly impacted $(p<0.05)$ the genus of Lactobacillus present in the colon (19\% and respectively 17.54\%), and they synergistically decrease the Lactobacillus abundance from 50.5\% in control to $3.8 \%$ in the AFB1 + GS dietary group.

The Lachnospira genus growth was stimulated significantly $(p<0.05)$ by AFB1 $(4.53 \%$ vs. $1.69 \%$ in control). GS administration doesn't affect the relative abundance of Lachnospira (1.93\%) as compared with control. However, a synergic effect on Lachnospyra abundance was obtained when AFB1 and GS were administered together. Aflatoxin B1 could also account for a significant growth of 3.03\% $(p<0.05)$ of the Campylobacter genus in AFB1 group and of 3.8\% in AFB1 + GS group while the grape seed meal had no noticeable effect compared to control ( $0.84 \%$ and $1 \%$ respectively).

Generally speaking the AFB1 impacted the relative abundance of the large intestine microbiota when compared to the control as seen in the heatmap from Figure 10. AFB1 stimulated some of the bacteria species such as Campylobacter, Lachnospira, and Megasphaera, bacteria from the Tremblayales order, the Paraprevotelaceae and Erysipelotrichaceae microbial families while suppressing bacteria like Lactobacillus and Prevotella, and some bacteria from the Lachnospiraceae family.

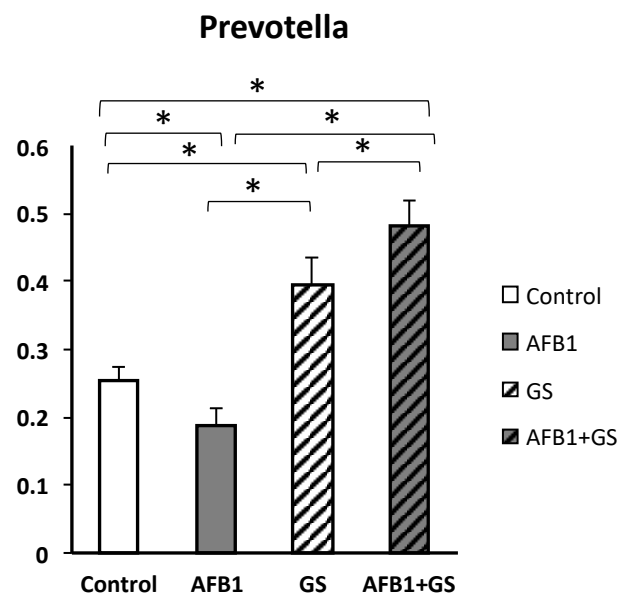

Campylobacter

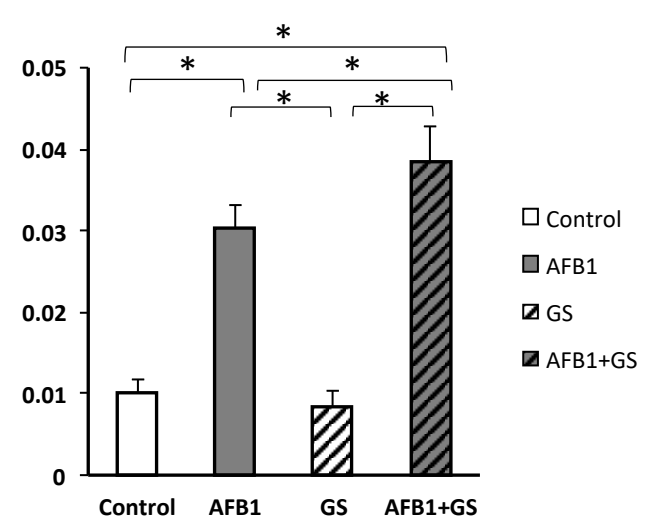

Lactobacillus

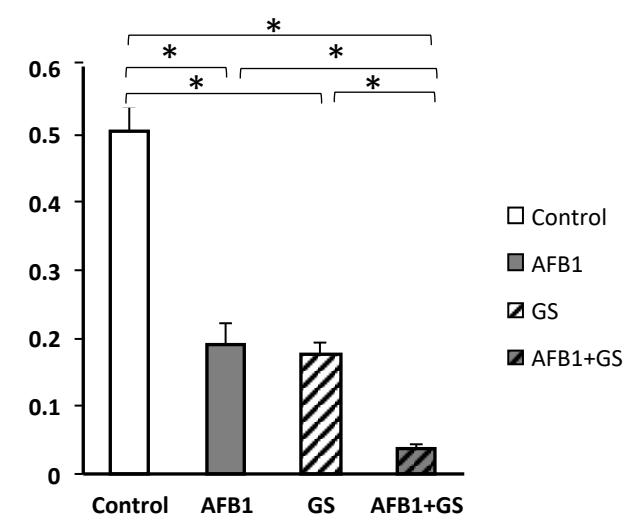

Lachnospira

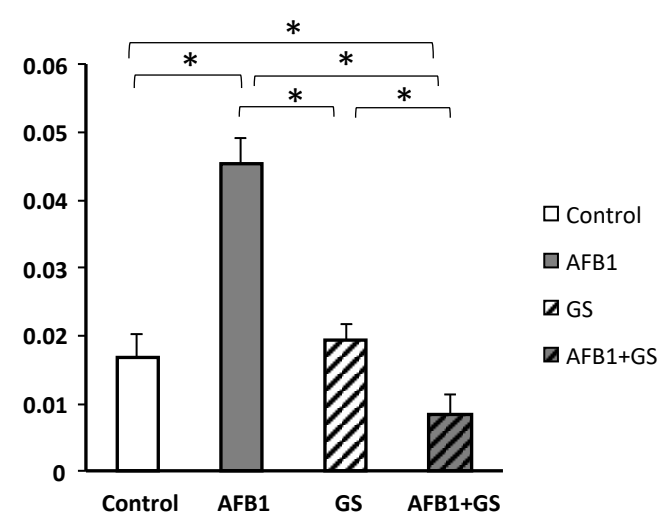

Figure 9. The relative abundances of the most important genus found in the content of colon of weanling piglets. GS: grape seed; AFB1: aflatoxin B1. ${ }^{*}$ indicate significant differences $(p<0.05)$ between groups. 


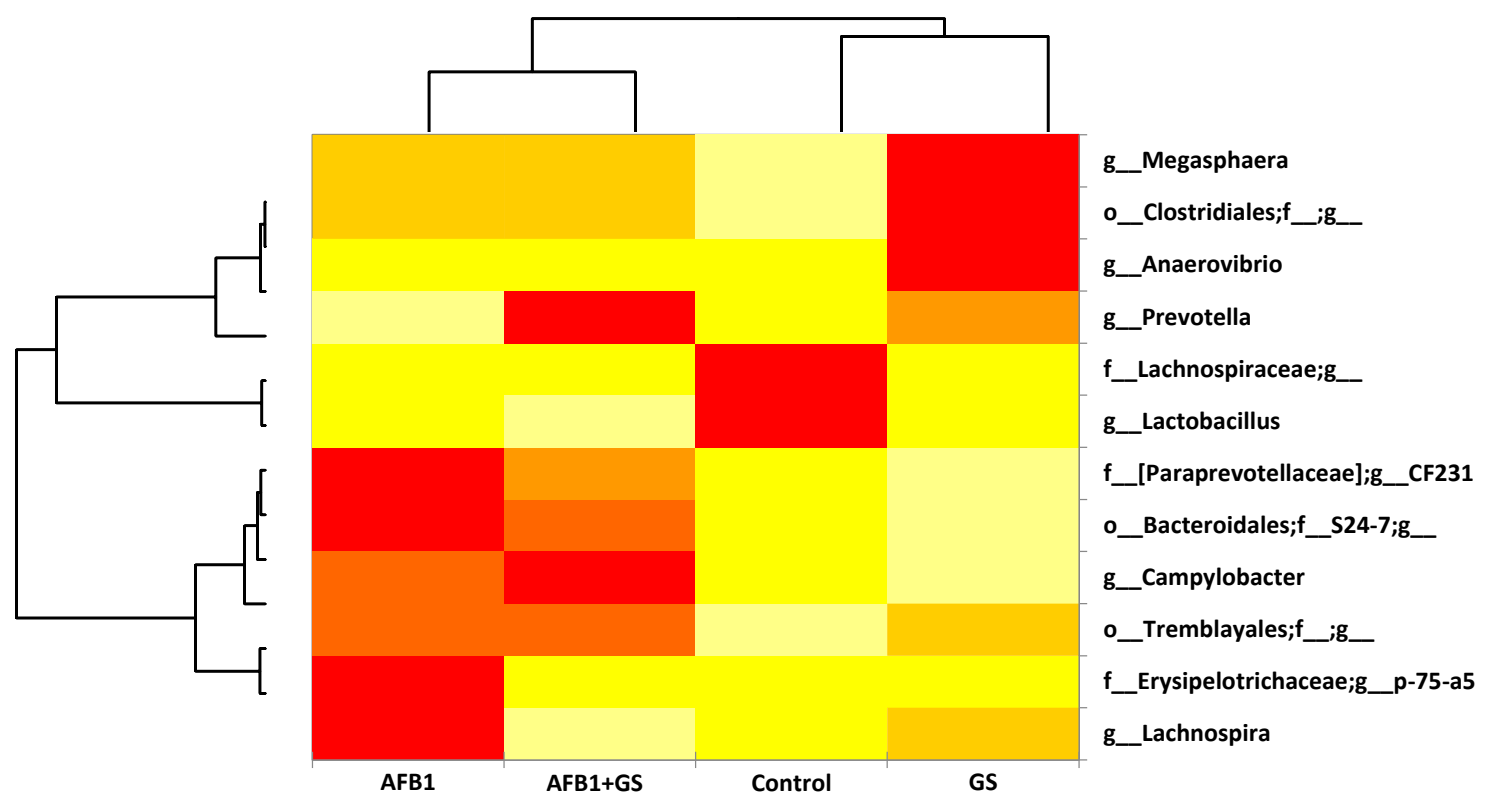

Figure 10. Heatmap illustrating the most important genus found in the content of the colon of weanling piglets. GS: grape seed; AFB1: aflatoxin B1.

On the other hand, the grape seed meal had an almost inverse effect to the AFB1 stimulating the growth of several bacterial species. It positively impacted the growth of Prevotella, Anaevibrio, and Megasphaera, Lachospira, some bacteria from the order Clostridiales and Tremblayales while suppressing the rest (Figure 10).

In the GS and AFB1 group the highest value of relative abundance was noted for Prevotella and Campylobacter, a modulation of the Paraprevotelaceae family and Bacteroidales and Tremblayales order, while diminishing Lachnospira and Lactobacillus to their lowest extent.

\section{Discussions}

The present study has demonstrated that the dynamics of the microbiota was changed by grape seed meal, aflatoxin B1 or their combinations and we have identified a complex microbiota in the large intestine of the piglets. This was consistent with the scientific reports which show that large intestine of pig has a high richness and diversity of microbiota [29]. In a comprehensive study published by Kim and collaborators [30] on the pig gastrointestinal microbiome, from a phylum level perspective, most bacteria were classified in five phyla: Firmicutes, Bacteroidetes, Proteobacteria, Actinobacteria, and Spirochaetes. In this study, bacteria from Firmicutes phylum represented the largest proportion of the total population followed by Bacteroidetes and these results were similar with our data concerning the distribution of the colon microbiota in piglets. Other studies have shown that these two phyla account for approximately $86-95 \%$ of all bacteria present in the large intestine [31].

The most abundant genus identified in the colon of control and experimental piglets from our study were represented by Prevotella, Lactobacillus, Lachnospira and Campylobacter. Also, the bioinformatic analysis allowed the identification of Megasphaera, Anaerovibrio, Trembayales, and Clostridiaceae.

Most of the bacteria identified in the colon content samples are known to play important roles in the metabolisms of carbohydrates, nucleotides, and amino acids [32]. Our results are similar with other studies that focused on the identification of the core fecal microbiota genus in the colon of the pigs, represented by: Clostridiales, Ruminococcaceae, Bacteroidetes, Escherichia, Firmicutes, Lactobacillus, Erysipelotrichaceae, Lachnospiraceae [33].

Grape seed meal is rich in polyphenols [34], but only $5-10 \%$ of the total polyphenol intake is absorbed in the small intestine, the remaining polyphenols (90-95\% of total polyphenol intake) being 
subject to the enzymatic activities of the gut microbial community [35]. There is evidence from in vitro animal and human studies that phenolic compounds alter gut microbiota and, consequently, alter the Bacteroides/Firmicutes balance [36,37]. The Firmicutes to Bacteroidetes ratio was linked to the general health of vertebrates [38].

In our study, the phylum Bacteroidetes was statistically and progressively increased as compared with control group after the addition of GS in the pig diet, while the Firmicutes phylum was significantly decreased by GS. Many studies have shown that dietary polyphenols and their metabolites contribute to the maintenance of gut health by the modulation of the gut microbial balance through the stimulation of the growth of beneficial bacteria and the inhibition of pathogen bacteria, exerting prebiotic-like effects [35]. Thus, it was shown that grape seed extracts may modulate the intestinal microbiota, producing changes in beneficial bacteria such as Lactobacillus spp. but inhibiting other groups such Clostridium spp. in both in vivo and in vitro studies $[9,37]$. However, in our study, GS has induced a significant decrease of Lactobacillus, Lachnospiraceae, Bacteroidales, and Campylobacter, while positively impacted other species like Megasphera, Clostridiales, Anaerovibrio, or Prevotella. The higher relative abundance of Megasphaera, Prevotella, and bacteria belonging to Clostridiales order that were found in pigs fed GS diet might have beneficial effects on the host due to the implications of these species in the carbohydrate metabolic chain and the synthesis of short chain fatty acids [39]. Prevotella, Megasphaera, Anaerovibrio represents strictly anaerobic bacteria that have been identified as a dominant species in the large intestine of pigs, and are also abundant in the ileum $[29,40,41]$. These bacteria are known to be a dominant complex carbohydrate degrading bacterial group in the lower gastrointestinal tract [42] and their increase in the colon of piglet fed a GS diet, might result in response to the higher fiber content of the diet enriched with grape seed meal.

A decrease of Lactobacillus abundance as well as an increase in relative abundance of Clostridium was already described in a recent study in rats fed with grape pomace extract rich in phenolic compounds [43]. Lactobacillus spp. is a beneficial bacterium that enhances gut barrier function, stimulates the host immune system, prevents diarrhea or allergies, contributes to activation of provitamins, and modulates lipid metabolism [44]. An increase or a reduction of growth of Lactobacillus was reported in several in vitro and in vivo studies depending on the precursor or the metabolite used. While some phenolic compounds (gallic acid, isoflavones, proanthocyanidins, and resveratrol) increase the relative abundance of Lactobacillus, other compounds, (catechin, epicatechin, quercetin) had no significant effect or even decrease the Lactobacillus abundance [45]. Studies on pigs fed grape pomace (GP) diets showed that GP decreases the relative abundance of Lactobacillus and Ruminococcus [46]. Also, the grape seed proanthocyanidins decreased the abundance of Lactobacillaceae and increased the abundance of Clostridiaceae in both ileal and colonic lumen [47].

Similar with our results, other in vivo studies using grape pomaces have shown an increase of Clostridiales abundance. For example, proanthocyanidins induce an increase of Clostridiales in pigs fed a diet containing 1\% grape seed extract [48] and Clostridium coccoides was increased by a wide variety of polyphenolic compounds both in vivo and in vitro [49-51].

The Clostridia belong to the class of Firmicutes and represent obligate anaerobes bacteria, including Clostridium and other similar genera [41]. Clostridium represent normal constituents of the intestinal flora, with different implication for animal health as some members of the Clostridiales family, as Clostridium difficile are associated with negative implications, such as inflammatory bowel disease [52], while others as C. leptum and C. coccoides are important members of the gut flora by promoting healthy aging [53].

Intoxication of pigs with AFB1 was associated with reduced feed intake and body weight gain, impaired liver and immune functions and altered serum biochemical parameters [54]. Indeed, our results have shown a significant decrease in the body weight of AFB1 intoxicated piglets. Even that diarrhea was less associated with aflatoxin B1 intoxication when compared with other mycotoxin as deoxynivalenol [55], our study has shown an increase of the number of pigs with diarrhea after the AFB1 administration as compared with the control. Also, in our experiment, intoxication with 
AFB1 induced compositional changes in microbial community, consisting in an increase of the phylum Bacteroidetes, while decreasing the Firmicutes phylum abundance, but the changes were opposites when compared with the changes induced by GS diet. Similar results were obtained also in rats exposed to different concentration of AFB1, species whose compositions significantly decreased among the top 20 OTUs belong mainly to Firmicutes, with an important decrease of Lactobacillus, mainly of Streptococcus sp. and Lactococcus sp. [1]. When looking to the species affected by the AFB1 exposure, the toxin induced a decrease of Prevotella and Lactobacillus in the colon of intoxicated piglets, while increasing Camplyobacter, Lachnospira and some members of Erysipelotrichaceae, Bacteroidales or Tremblayales families. Earlier studies have shown that the antimicrobial spectrum of aflatoxin B1 is narrow and limited and AFB1 was found to be inactive against common Gram-positive and Gram-negative bacteria at a concentration of $100 \mu \mathrm{g} / \mathrm{mL}$ [56]. Thus, a general antimicrobial effect cannot explain the alterations of microbiota found in the colon of intoxicated animals. It rather looks that other more complex mechanisms can be involved and it was suggested that the gut microbiota of a host could be intentionally modified to accumulate toxin-tolerant species, a potential natural biological intervention strategy for mitigation of AFB1-induced toxic effect [1]. For example, it has been reported that some lactic acid bacteria can remove AFB1 or have protective effects against AFB1 [57,58]. Indeed, an increase of AFB1 concentration in feces was observed in intoxicated mice receiving L. plantarum as compared with mice receiving only AFB1 [59].

Less piglets with diarrhea were observed in the group fed AFB1 + GS diet as compared with AFB1 group, suggesting that GS was responsible for a shift in the microbiota that results in a reduction of diarrhea. Concomitant administration of GS and AFB1 caused significant shift in the microbial community by significantly increasing the relative abundance of phylum Bacteroidetes and Proteobacteria, while decreasing the Firmicutes abundance in a synergic or additive manner as compared with the individual treatments. Again, an additive or synergistic action of the two treatments was identified for Lactobacillus, Prevotella, and Campylobacter, while rather an antagonistic effect was observed on Lachnospira. Lachnospira decrease observed in the colon of piglets fed both AFB1 and GS can be correlated with the reduction of diarrhea incidence as compared with AFB1 group, as Lachnospira is positively correlated with diarrhea in piglets [60]. Also, it was shown that the abundance of Prevotella was increased in healthy pigs compared with pigs with diarrhea and the higher abundance of Prevotellaceae family in healthy pigs may provide an adequate prevention strategy for pathogen infection [61]. However, our microbiota results cannot entirely explain the beneficial effect of grape seed meal, and other microbiota-independent mechanisms might be responsible for the positive effects of the grapeseed meal in weaned piglets. Indeed, our preliminary data have shown that the inclusion of grape seed in the diet of AFB1 intoxicated pigs restored toward the control group the level of the phase-II antioxidant enzymes activity and total antioxidant capacity, decreased TBARS level, and had the potential to ameliorate the pro-inflammatory cytokines concentration and the performance of AFB1-treated animals (unpublished data).

In conclusion, piglets fed for 30 days with a diet contaminated with AFB1 registered a significantly lower body weight and a high frequency of diarrhea. These effects were counteracted at least partially by the inclusion of $8 \%$ GS meal into the diet contaminated with AFB1. In the analyses concerning large intestine microbiota 157 numbers of OTUs were identified among all four dietary groups with 26 of them being prevalent above $0.05 \%$ in the total relative abundance. Most of the OTUs were identified as bacteria involved in polysaccharides (hemicellulose and pectin, host glycan, and $\alpha$-glucan) and carboxylic and amino acid metabolism. Concomitant administration of GS and AFB1 caused significant shift in the microbial community by significantly increasing the relative abundance of phylum Bacteroidetes and Proteobacteria, while decreasing the Firmicutes abundance in a synergic or additive manner as compared with the individual treatments. Again, an additive or synergistic action of the two treatments was identified for Lactobacillus, Prevotella and Campylobacter, while rather an antagonistic effect was observed on and Lachnospira. The action mechanisms of aflatoxin B1 and 
grape seed meal that drive the large intestine microbiota to these changes are not known and need further investigations.

\section{Materials and Methods}

\subsection{Animals and Diets}

Animals were handled in accordance with the Romanian Law 206/2004 and the EU Council Directive 98/58/EC for handling and protection of animals used for experimental purposes. The study protocol was approved by the Ethical Committee of the National Research-Development Institute for Animal Nutrition and Biology, Balotesti, Romania (Ethical Committee no. 52/2014, Date of approval: 10 March 2014).

Twenty-four healthy weaned crossbred TOPIGS-40 hybrid piglets, with an average body weight of $9.13 \pm 0.03 \mathrm{~kg}$ were allocated into four groups of 6 piglets based on diet composition as follows: (1) Control group fed a standard diet; (2) AFB1 group fed a diet contaminated with $320 \mu \mathrm{g} / \mathrm{kg}$ AFB1; (3) GS group fed a diet supplemented with a 8\% grape seed meal; (4) AFB1 + GS group fed a diet containing both $320 \mu \mathrm{g} / \mathrm{kg}$ AFB1 and $8 \%$ grape seed meal. The grape seed meal provided by a local commercial (S.C. OLEOMET-SA S.R.L., Bucuresti, Romania) was included in the diet by corn replacement. The total polyphenol content and identification of different classes of polyphenols of grape seed meal was measured by the Folin-Ciocalteu reaction and HPLC-DAD-MS and gas chromatography as described by [62]. The polyphenols composition of the grape seed meal is presented in Table 1.

Table 1. The composition in polyphenols of the grape seed meal.

\begin{tabular}{cc}
\hline Polyphenols & Grape Seed Meal \\
\hline Total polyphenols (mg GAE eq/100 g) & 5567.2 \\
Phenolic compound (mg Quercitin eq/100 g) & \\
Ferulic acid derivative & 24.10 \\
Caffeoilquinic acid & 40.15 \\
Procianidin trimer & 9.11 \\
Catechin & 9.53 \\
Epicatechin & 8.51 \\
Gallocatechin & 8.60 \\
Epigalocatechin & 15.60 \\
Procianidin dimer & 11.09 \\
Petunidin 3-O-glucoside & 12.15 \\
Procianidin dimer & 10.08 \\
Ferulic acid & 12.43 \\
Cianidin coumaroil-glucoside & 12.79 \\
Malvidin coumaroil-glucoside & 14.26 \\
Dicaffeoilquinic acid & 19.50 \\
Dicaffeoilquinic acid & 20.20 \\
\hline
\end{tabular}

To prepare the toxin contaminated diet, $50 \mathrm{mg}$ AFB1 (FERMENTEC, Jerusalem, Israel) was dissolved in DMSO (dymethil sulfoxide) and mixed into basal diet to provide a feed diet containing $320 \mu \mathrm{g} / \mathrm{kg}$; final AFB1 concentration in feed was verified by ELISA using a Veratox kit (Neogen, Lansing, MI, USA). The content of other mycotoxins that frequently contaminate cereals (DON, ZEA, OTA) was under the detection limit as resulted from the ELISA assay.

The animals were individually identified by ear tag and housed in pens (two replicates of 3 pigs per pen per treatment) and fed the experimental diets for 30 days. They had free access to feed and water every day of the experimental period. The piglets with diarrhea were recorded every day of the experiment. All diets were formulated to meet specific requirements for weaning feed as indicated by NRC (2012) - Table 2. At the end of the experiment pigs were weighted and then slaughtered. The content of the colon was immediately frozen and stored at $-80^{\circ} \mathrm{C}$ until use. 
Table 2. Composition of experimental diet (\%).

\begin{tabular}{ccccc}
\hline Ingredients (\%) & Control & AFB1 & GS & GS + AFB1 \\
\hline Corn & 67.47 & 67.47 & 58.5 & 58.5 \\
Soybean meal & 19 & 19 & 18 & 18 \\
Gluten & 4 & 4 & 4 & 4 \\
Milk replacer & 5 & 5 & 5 & 5 \\
Soya oil & - & - & 2 & 2 \\
L Lysine & 0.4 & 0.4 & 0.4 & 0.4 \\
DL Methionine & 0.1 & 0.1 & 0.15 & 0.15 \\
Monocalcium phosphate & 1.46 & 1.46 & 1.33 & 1.33 \\
Feed grade limestone & 1.37 & 1.37 & 1.42 & 1.42 \\
Salt & 0.1 & 0.1 & 0.1 & 0.1 \\
Choline premix & 0.1 & 0.1 & 0.1 & 0.1 \\
Vitamin mineral premix 1 & 1 & 1 & 1.0 & 1.0 \\
Grape seed meal & - & - & 8 & 8 \\
AFB1 (mg/kg) & - & 320 & - & 320 \\
Analyzed composition & & & & \\
\hline EM (kcal/kg) & 3248 & 3248 & 3178 & 3178 \\
Crude protein \% & 18.42 & 18.42 & 18.21 & 18.21 \\
Lisine \% & 1.2 & 1.2 & 1.2 & 1.2 \\
Methionine +Cysteine\% & 0.72 & 0.72 & 0.72 & 0.72 \\
Ca\% & 0.9 & 0.9 & 0.9 & 0.9 \\
P\% & 0.65 & 0.65 & 0.65 & 0.65 \\
Fat $\%$ & 3.03 & 3.03 & 3.19 & 3.19 \\
Celulose $\%$ & 3.12 & 3.12 & 5.8 & 5.8 \\
\hline
\end{tabular}

${ }^{1}$ Vitamin-mineral premix/ $\mathrm{kg}$ diet: (0-18 days): 10,000 UI vit. A; 2000 vit. D; 30 UI vit. E; $2 \mathrm{mg}$ vit. K; $1.96 \mathrm{mg}$ vit. $\mathrm{B}_{1} ; 3.84 \mathrm{mg}$ vit. $\mathrm{B}_{2} ; 14.85 \mathrm{mg}$ pantothenic ac.; $19.2 \mathrm{mg}$ nicotinic ac.; $2.94 \mathrm{mg}$ vit. $\mathrm{B}_{6} ; 0.98 \mathrm{mg}$ folic ac.; $0.03 \mathrm{mg}$ vit. $\mathrm{B}_{12}$; 0.06 biotin; $24.5 \mathrm{mg}$ vit. C; $40.3 \mathrm{mg} \mathrm{Mn} ; 100 \mathrm{mg} \mathrm{Fe;} 100 \mathrm{mg} \mathrm{Cu} ; 100 \mathrm{mg} \mathrm{Zn;} 0.38$ I; $0.23 \mathrm{mg}$ Se.

\subsection{Microbial DNA Extraction and $16 S$ rRNA Gene Sequencing}

Microbial DNA was extracted using the QIAamp DNA stool minikit (QIAGEN, Dusseldorf, Germany) following the manufacturer protocol additionally increasing the temperature to $95^{\circ} \mathrm{C}$ to improve the DNA yield. Sample DNA concentrations were verified on agarose gel electrophoresis and on the Nanodrop Spectrophotometer and adjusted to $10 \mathrm{ng} / \mu \mathrm{L}$ with a volume of $100 \mu \mathrm{L}$ for each sample for a total of 24 samples.

Microbial profiling was performed by BMR Genomics (Padova, Italy) using the Illumina Miseq platform using 300PE approach on $16 \mathrm{~S}$ amplicons derived from the bacterial DNA. The library formation and sequencing of the 16S rRNA genes were carried out according to the method above. In the first step the V3 and V4 regions of the amplicons were amplified with universal primers: forward primer: $5^{\prime}$-CCTACGGGAGGCAGCAGT-3' and reverse primer 5'-GACTACCAGGGTATCTAATCCTGTT-3' [63] and forward primer: 5'-CCTACGGGNBGCASCAG-3' and reverse primer: $5^{\prime}$-GACTACNVGGGTATCTAATCC-3' [64]. In the second amplification step, the adaptors and indexes were bound to the sequences. The pooling of the samples was followed by a cluster generation and sequencing with the Paired End $2 \times 300 \mathrm{pb}$ format.

\subsection{Microbiota Bioinformatics}

For the microbial raw data, the sequences obtained were investigated using a subsampled open reference OTU (operational taxonomic unit) picking method with default settings performed in QIIME (v1.9.1). The 16S rRNA gene reads were then paired-end and demultiplexed. Subsampled open-reference analyzable samples were clustered into Operational Taxonomic Units. The OTU-picking strategy was carried out by using UCLUST algorithm using a de-novo strategy with a $97 \%$ sequence similarity threshold. Representative sequences for each OTU were set in a matchup with the Greengenes database V13_8 and taxonomy was designated through the application of the UCLUST 
method with a $90 \%$ confidence threshold. Data was chimera checked using the Blast fragments approach in QIIME. The raw reads in QIIME were filtered for a length $\geq 70$ and an average quality $\geq 20$. In order to eliminate sampling depth heterogeneity, the OTU table was rarefied to the lowest number of reads obtained from a single sample. Furthermore, the OTU table obtained in the previous step was abundance filtered by removing the OTUs with a relative abundance $\leq 0.005 \%$ across all samples in order to keep only the most abundant species for further data processing.

A phylogenetic tree was constructed by firstly aligning the representative sequences of each OTU using PyNAST algorithm against Greengene reference sequences. Above mentioned procedures were implemented through QIIME with customized commands. The OTU table and phylogenetic tree were the major elements for data analysis.

The diversity was estimated with Chao 1 and Faith's phylogenetic diversity (PD_whole_tree) observed-species indices (alpha or within-sample diversity) and double principal component analysis (DPCoA; beta or between-sample diversity) using the phylogeny-based weighted Unifrac distance matrix.

A heatmap was also built around the OTU table of the species that were found above a $0.005 \%$ relative abundance.

\subsection{Statistical Analysis}

Analyses were performed using XLstat software package (http:/ / www.xlstat.com). Comparison between groups was performed using one-way analysis of variance (ANOVA) with the post hoc Tukey test for multiple comparisons at the $p<0.05$ level. ANOSIM is an internal statistical method (script) of the QIIME which was used to test the differences between two or more samples. The ANOSIM test is nonparametric and the statistical significance is derived through permutations.

Author Contributions: D.E.M. and I.T. realized the design of the experiment. I.A.G. and G.C.P. performed the DNA extraction. I.A.G. analyzed the raw microbiota data. I.A.G. and D.E.M. wrote the manuscript.

Funding: The experimental work of this study was supported by funds from the National Research Project PNIII-PED-189/2017-2018. The publication was supported by funds from the National Research Development Project Projects to finance excellence (PFE)- 17/2018-2020 granted by the Romanian Ministry of Research and Innovation.

Acknowledgments: The authors thanks to Catarina Gosh and to Mihai Roman for proof reading this manuscript

Conflicts of Interest: The authors declare no conflict of interest.

\section{References}

1. Wang, J.; Tang, L.; Glenn, T.C.; Wang, J.S. Aflatoxin B1 induced compositional changes in gut microbial communities of male F344 rats. Toxicol. Sci. 2016, 150, 54-63. [CrossRef] [PubMed]

2. Alassane-Kpembi, I.; Schatzmayr, G.; Taranu, I.; Marin, D.; Puel, O.; Oswald, I.P. Mycotoxins co-contamination: Methodological aspects and biological relevance of combined toxicity studies. Crit. Rev. Food Sci. Nutr. 2017, 57, 3489-3507. [CrossRef] [PubMed]

3. Zhou, J.; Tang, L.; Wang, J.; Wang, J.S. Aflatoxin B1 disrupts gut-microbial metabolisms of short-chain fatty acids, long-chain fatty acids, and bile acids in male f344 rats. Toxicol. Sci. 2018, 164, 453-464. [CrossRef] [PubMed]

4. Streit, E.; Schatzmayr, G.; Tassis, P.; Tzika, E.; Marin, D.; Taranu, I.; Tabuc, C.; Nicolau, A.; Aprodu, I.; Puel, O.; et al. Current situation of mycotoxin contamination and co-occurrence in animal feed-focus on Europe. Toxins 2012, 4, 788-809. [CrossRef] [PubMed]

5. Marin, D.E.; Taranu, I. Overview on aflatoxins and oxidative stress. Toxin Rev. 2012, 31, 32-43. [CrossRef]

6. Pierron, A.; Alassane-Kpembi, I.; Oswald, I.P. Impact of mycotoxin on immune response and consequences for pig health. Anim. Nutr. 2016, 2, 63-68. [CrossRef] [PubMed]

7. Umesha, S.; Manukumar, H.M.; Chandrasekhar, B.; Shivakumara, P.; Shiva Kumar, J.; Raghava, S.; Avinash, P.; Shirin, M.; Bharathi, T.R.; Rajini, S.B.; et al. Aflatoxins and food pathogens: Impact of biologically active aflatoxins and their control strategies. J. Sci. Food Agric. 2017, 97, 1698-1707. [CrossRef] 
8. Duenas, M.; Munoz-Gonzalez, I.; Cueva, C.; Jimenez-Giron, A.; Sanchez-Patan, F.; Santos-Buelga, C.; Moreno-Arribas, M.V.; Bartolome, B. A survey of modulation of gut microbiota by dietary polyphenols. BioMed Res. Int. 2015, 2015, 850902. [CrossRef] [PubMed]

9. Viveros, A.; Chamorro, S.; Pizarro, M.; Arija, I.; Centeno, C.; Brenes, A. Effects of dietary polyphenol-rich grape products on intestinal microflora and gut morphology in broiler chicks. Poult. Sci. 2011, 90, 566-578. [CrossRef] [PubMed]

10. Jara-Palacios, M.J.; Hernanz, D.; Cifuentes-Gomez, T.; Escudero-Gilete, M.L.; Heredia, F.J.; Spencer, J.P. Assessment of white grape pomace from winemaking as source of bioactive compounds, and its antiproliferative activity. Food Chem. 2015, 183, 78-82. [CrossRef] [PubMed]

11. Ky, I.; Teissedre, P.L. Characterisation of mediterranean grape pomace seed and skin extracts: Polyphenolic content and antioxidant activity. Molecules 2015, 20, 2190-2207. [CrossRef]

12. Amiot, M.J.; Riva, C.; Vinet, A. Effects of dietary polyphenols on metabolic syndrome features in humans: A systematic review. Obes. Rev. 2016, 17, 573-586. [CrossRef] [PubMed]

13. Lu, H.; Liu, F.; Zhu, Q.; Zhang, M.; Li, T.; Chen, J.; Huang, Y.; Wang, X.; Sheng, J. Aflatoxin B1 can be complexed with oxidised tea polyphenols and the absorption of the complexed aflatoxin B1 is inhibited in rats. J. Sci. Food Agric. 2017, 97, 1910-1915. [CrossRef] [PubMed]

14. Brenes, A.; Viveros, A.; Chamorro, S.; Arija, I. Use of polyphenol-rich grape by-products in monogastric nutrition. A review. Anim. Feed Sci. Technol. 2016, 211, 1-17. [CrossRef]

15. Xu, H.; Wang, L.; Su, H.; Gu, L.; Han, T.; Meng, F.; Liu, C. Making good use of food wastes: Green synthesis of highly stabilized silver nanoparticles from grape seed extract and their antimicrobial activity. Food Biophys. 2014, 10, 12-18. [CrossRef]

16. Shi, J.; Yu, J.; Pohorly, J.E.; Kakuda, Y. Polyphenolics in grape seeds-biochemistry and functionality. J. Med. Food 2003, 6, 291-299. [CrossRef]

17. Zhang, H.; Tsao, R. Dietary polyphenols, oxidative stress and antioxidant and anti-inflammatory effects. Curr. Opin. Food Sci. 2016, 8, 33-42. [CrossRef]

18. Firozi, P.F.; Bhattacharya, R.K. Effects of natural polyphenols on aflatoxin B1 activation in a reconstituted microsomal monooxygenase system. J. Biochem. Toxicol. 1995, 10, 25-31. [PubMed]

19. Rowland, I.; Gibson, G.; Heinken, A.; Scott, K.; Swann, J.; Thiele, I.; Tuohy, K. Gut microbiota functions: Metabolism of nutrients and other food components. Eur. J. Nutr. 2018, 57, 1-24. [CrossRef] [PubMed]

20. Hooper, L.V.; Littman, D.R.; Macpherson, A.J. Interactions between the microbiota and the immune system. Science 2012, 336, 1268-1273. [CrossRef]

21. Niu, Q.; Li, P.; Hao, S.; Zhang, Y.; Kim, S.W.; Li, H.; Ma, X.; Gao, S.; He, L.; Wu, W.; et al. Dynamic distribution of the gut microbiota and the relationship with apparent crude fiber digestibility and growth stages in pigs. Sci. Rep. 2015, 5, 9938. [CrossRef] [PubMed]

22. Boyer, J.; Liu, R.H. Apple phytochemicals and their health benefits. Nutr. J. 2004, 3, 5. [CrossRef] [PubMed]

23. Murota, K.; Nakamura, Y.; Uehara, M. Flavonoid metabolism: The interaction of metabolites and gut microbiota. Biosci. Biotechnol. Biochem. 2018, 82, 600-610. [CrossRef] [PubMed]

24. Fiesel, A.; Gessner, D.K.; Most, E.; Eder, K. Effects of dietary polyphenol-rich plant products from grape or hop on pro-inflammatory gene expression in the intestine, nutrient digestibility and faecal microbiota of weaned pigs. BMC Vet. Res. 2014, 10, 196. [CrossRef] [PubMed]

25. Ritchie, L.E.; Sturino, J.M.; Carroll, R.J.; Rooney, L.W.; Azcarate-Peril, M.A.; Turner, N.D. Polyphenol-rich sorghum brans alter colon microbiota and impact species diversity and species richness after multiple bouts of dextran sodium sulfate-induced colitis. FEMS Microbiol. Ecol. 2015, 91. [CrossRef] [PubMed]

26. Yang, H.; Huang, X.; Fang, S.; He, M.; Zhao, Y.; Wu, Z.; Yang, M.; Zhang, Z.; Chen, C.; Huang, L. Unraveling the fecal microbiota and metagenomic functional capacity associated with feed efficiency in pigs. Front. Microbiol. 2017, 8, 1555. [CrossRef] [PubMed]

27. Liehr, M.; Mereu, A.; Pastor, J.J.; Quintela, J.C.; Staats, S.; Rimbach, G.; Ipharraguerre, I.R. Olive oil bioactives protect pigs against experimentally-induced chronic inflammation independently of alterations in gut microbiota. PLoS ONE 2017, 12, e0174239. [CrossRef] [PubMed]

28. Kiros, T.G.; Derakhshani, H.; Pinloche, E.; D’Inca, R.; Marshall, J.; Auclair, E.; Khafipour, E.; Van Kessel, A. Effect of live yeast saccharomyces cerevisiae (actisaf sc 47) supplementation on the performance and hindgut microbiota composition of weanling pigs. Sci. Rep. 2018, 8, 5315. [CrossRef] [PubMed] 
29. Kim, H.B.; Isaacson, R.E. The pig gut microbial diversity: Understanding the pig gut microbial ecology through the next generation high throughput sequencing. Vet. Microbiol. 2015, 177, 242-251. [CrossRef] [PubMed]

30. Kim, H.B.; Borewicz, K.; White, B.A.; Singer, R.S.; Sreevatsan, S.; Tu, Z.J.; Isaacson, R.E. Longitudinal investigation of the age-related bacterial diversity in the feces of commercial pigs. Vet. Microbiol. 2011, 153, 124-133. [CrossRef] [PubMed]

31. McCormack, U.M.; Curiao, T.; Buzoianu, S.G.; Prieto, M.L.; Ryan, T.; Varley, P.; Crispie, F.; Magowan, E.; Metzler-Zebeli, B.U.; Berry, D.; et al. Exploring a possible link between the intestinal microbiota and feed efficiency in pigs. Appl. Environ. Microbiol. 2017, 83. [CrossRef] [PubMed]

32. Tian, G.; Wu, X.; Chen, D.; Yu, B.; He, J. Adaptation of gut microbiome to different dietary nonstarch polysaccharide fractions in a porcine model. Mol. Nutr. Food Res. 2017, 61. [CrossRef] [PubMed]

33. Zhao, W.; Wang, Y.; Liu, S.; Huang, J.; Zhai, Z.; He, C.; Ding, J.; Wang, J.; Wang, H.; Fan, W.; et al. The dynamic distribution of porcine microbiota across different ages and gastrointestinal tract segments. PLOS ONE 2015, 10, e0117441. [CrossRef] [PubMed]

34. Georgiev, V.; Ananga, A.; Tsolova, V. Recent advances and uses of grape flavonoids as nutraceuticals. Nutrients 2014, 6, 391-415. [CrossRef] [PubMed]

35. Cardona, F.; Andrés-Lacueva, C.; Tulipani, S.; Tinahones, F.J.; Queipo-Ortuño, M.I. Benefits of polyphenols on gut microbiota and implications in human health. J. Nutr. Biochem. 2013, 24, 1415-1422. [CrossRef] [PubMed]

36. Lee, H.C.; Jenner, A.M.; Low, C.S.; Lee, Y.K. Effect of tea phenolics and their aromatic fecal bacterial metabolites on intestinal microbiota. Res. Microbiol. 2006, 157, 876-884. [CrossRef]

37. Hervert-Hernandez, D.; Pintado, C.; Rotger, R.; Goni, I. Stimulatory role of grape pomace polyphenols on lactobacillus acidophilus growth. Int. J. Food Microbiol. 2009, 136, 119-122. [CrossRef]

38. O'Donnell, M.M.; Harris, H.M.B.; Ross, R.P.; O'Toole, P.W. Core fecal microbiota of domesticated herbivorous ruminant, hindgut fermenters, and monogastric animals. Microbiologyopen 2017, 6. [CrossRef]

39. Morris, G.; Berk, M.; Carvalho, A.; Caso, J.R.; Sanz, Y.; Walder, K.; Maes, M. The role of the microbial metabolites including tryptophan catabolites and short chain fatty acids in the pathophysiology of immune-inflammatory and neuroimmune disease. Mol. Neurobiol. 2017, 54, 4432-4451. [CrossRef]

40. Leser, T.D.; Amenuvor, J.Z.; Jensen, T.K.; Lindecrona, R.H.; Boye, M.; Møller, K. Culture-independent analysis of gut bacteria: The pig gastrointestinal tract microbiota revisited. Appl. Environ. Microbiol. 2002, 68, 673-690. [CrossRef]

41. Yutin, N.; Galperin, M.Y. A genomic update on clostridial phylogeny: Gram-negative spore formers and other misplaced clostridia. Environ. Microbiol. 2013, 15, 2631-2641. [CrossRef] [PubMed]

42. Shah, H.N.; Collins, D.M. Prevotella, a new genus to include bacteroides melaninogenicus and related species formerly classified in the genus bacteroides. Int. J. Syst. Bacteriol. 1990, 40, 205-208. [CrossRef] [PubMed]

43. Chacar, S.; Itani, T.; Hajal, J.; Saliba, Y.; Louka, N.; Faivre, J.F.; Maroun, R.; Fares, N. The impact of long-term intake of phenolic compounds-rich grape pomace on rat gut microbiota. J. Food Sci. 2018, 83, $246-251$. [CrossRef] [PubMed]

44. Burcelin, R.; Garidou, L.; Pomie, C. Immuno-microbiota cross and talk: The new paradigm of metabolic diseases. Semin. Immunol. 2012, 24, 67-74. [CrossRef]

45. Ozdal, T.; Sela, D.A.; Xiao, J.; Boyacioglu, D.; Chen, F.; Capanoglu, E. The reciprocal interactions between polyphenols and gut microbiota and effects on bioaccessibility. Nutrients 2016, 8, 78. [CrossRef] [PubMed]

46. Williams, A.R.; Krych, L.; Fauzan Ahmad, H.; Nejsum, P.; Skovgaard, K.; Nielsen, D.S.; Thamsborg, S.M. A polyphenol-enriched diet and Ascaris suum infection modulate mucosal immune responses and gut microbiota composition in pigs. PLoS ONE 2017, 12, e0186546. [CrossRef]

47. Han, M.; Song, P.; Huang, C.; Rezaei, A.; Farrar, S.; Brown, M.A.; Ma, X. Dietary grape seed proanthocyanidins (GSPs) improve weaned intestinal microbiota and mucosal barrier using a piglet model. Oncotarget 2016, 7 , 80313-80326. [CrossRef]

48. Choy, Y.Y.; Quifer-Rada, P.; Holstege, D.M.; Frese, S.A.; Calvert, C.C.; Mills, D.A.; Lamuela-Raventos, R.M.; Waterhouse, A.L. Phenolic metabolites and substantial microbiome changes in pig feces by ingesting grape seed proanthocyanidins. Food Funct. 2014, 5, 2298-2308. [CrossRef] 
49. Clavel, T.; Fallani, M.; Lepage, P.; Levenez, F.; Mathey, J.; Rochet, V.; Serezat, M.; Sutren, M.; Henderson, G.; Bennetau-Pelissero, C.; et al. Isoflavones and functional foods alter the dominant intestinal microbiota in postmenopausal women. J. Nutr. 2005, 135, 2786-2792. [CrossRef]

50. Tzounis, X.; Vulevic, J.; Kuhnle, G.G.; George, T.; Leonczak, J.; Gibson, G.R.; Kwik-Uribe, C.; Spencer, J.P. Flavanol monomer-induced changes to the human faecal microflora. Br. J. Nutr. 2008, 99, 782-792. [CrossRef]

51. Bialonska, D.; Kasimsetty, S.G.; Schrader, K.K.; Ferreira, D. The effect of pomegranate (Punica granatum L.) byproducts and ellagitannins on the growth of human gut bacteria. J. Agric. Food Chem. 2009, 57, 8344-8349. [CrossRef] [PubMed]

52. Rastall, R.A.; Gibson, G.R.; Gill, H.S.; Guarner, F.; Klaenhammer, T.R.; Pot, B.; Reid, G.; Rowland, I.R.; Sanders, M.E. Modulation of the microbial ecology of the human colon by probiotics, prebiotics and synbiotics to enhance human health: An overview of enabling science and potential applications. FEMS Microbiol. Ecol. 2005, 52, 145-152. [CrossRef] [PubMed]

53. Lopetuso, L.R.; Scaldaferri, F.; Petito, V.; Gasbarrini, A. Commensal clostridia: Leading players in the maintenance of gut homeostasis. Gut Pathog. 2013, 5, 23. [CrossRef] [PubMed]

54. Devreese, M.; De Backer, P.; Croubels, S. Overview of the most important mycotoxins for the pig and poultry husbandry. Vlaams Diergeneeskd. Tijdschr. 2013, 82, 171-180.

55. Bonnet, M.S.; Roux, J.; Mounien, L.; Dallaporta, M.; Troadec, J.D. Advances in deoxynivalenol toxicity mechanisms: The brain as a target. Toxins 2012, 4, 1120-1138. [CrossRef] [PubMed]

56. Arai, T.; Ito, T.; Koyama, Y. Antimicrobial activity of aflatoxins. J. Bacteriol. 1967, 93, 59-64. [PubMed]

57. Gomaa, E.Z.; Abdelall, M.F.; El-Mahdy, O.M. Detoxification of aflatoxin B1 by antifungal compounds from lactobacillus brevis and lactobacillus paracasei, isolated from dairy products. Probiotics Antimicrob. Proteins 2018, 10, 201-209. [CrossRef] [PubMed]

58. Gratz, S.; Mykkanen, H.; El-Nezami, H. Aflatoxin B1 binding by a mixture of lactobacillus and propionibacterium: In vitro versus ex vivo. J. Food Prot. 2005, 68, 2470-2474. [CrossRef]

59. Huang, L.; Duan, C.; Zhao, Y.; Gao, L.; Niu, C.; Xu, J.; Li, S. Reduction of aflatoxin B1 toxicity by Lactobacillus plantarum C88: A potential probiotic strain isolated from chinese traditional fermented food "Tofu". PLoS ONE 2017, 12, e0170109. [CrossRef]

60. Zhu, J.J.; Gao, M.X.; Song, X.J.; Zhao, L.; Li, Y.W.; Hao, Z.H. Changes in bacterial diversity and composition in the faeces and colon of weaned piglets after feeding fermented soybean meal. J. Med. Microbiol. 2018, 67, 1181-1190. [CrossRef]

61. Dou, S.; Gadonna-Widehem, P.; Rome, V.; Hamoudi, D.; Rhazi, L.; Lakhal, L.; Larcher, T.; Bahi-Jaber, N.; Pinon-Quintana, A.; Guyonvarch, A.; et al. Characterisation of early-life fecal microbiota in susceptible and healthy pigs to post-weaning diarrhoea. PLoS ONE 2017, 12, e0169851. [CrossRef] [PubMed]

62. Taranu, I.; Habeanu, M.; Gras, M.A.; Pistol, G.C.; Lefter, N.; Palade, M.; Ropota, M.; Sanda Chedea, V.; Marin, D.E. Assessment of the effect of grape seed cake inclusion in the diet of healthy fattening-finishing pigs. J. Anim. Physiol. Anim. Nutr. 2018, 102, e30-e42. [CrossRef] [PubMed]

63. Nadkarni, M.A.; Martin, F.E.; Jacques, N.A.; Hunter, N. Determination of bacterial load by real-time PCR using a broad-range (universal) probe and primers set. Microbiology 2002, 148, 257-266. [CrossRef] [PubMed]

64. Takahashi, S.; Tomita, J.; Nishioka, K.; Hisada, T.; Nishijima, M. Development of a prokaryotic universal primer for simultaneous analysis of bacteria and archaea using next-generation sequencing. PLoS ONE 2014, 9, e105592. [CrossRef] [PubMed]

(C) 2019 by the authors. Licensee MDPI, Basel, Switzerland. This article is an open access article distributed under the terms and conditions of the Creative Commons Attribution (CC BY) license (http:/ / creativecommons.org/licenses/by/4.0/). 